\title{
Effects of coagulation temperature on the texture and yield of soy paneer (tofu)
}

\author{
S.S. Mathare ${ }^{1}$, S.B. Bakal ${ }^{1}$ T.M.R. Dissanayake ${ }^{2^{*}}$ and S.K. Jain ${ }^{1}$ \\ ${ }^{1}$ Department of Processing and Food Engineering, College of Technology and Engineering,MPUAT, Udaipur (Raj.), India. \\ 2 Institute of Postharvest Technology, Jayanthi Mawatha, Anuradhapura.
}

Revised: 04 May 2009 ; Accepted: 11 June 2009

\begin{abstract}
A study was conducted to find the effect of coagulation temperature on textural properties and yield of soy paneer coagulated with calcium sulfate. Suitability of soy paneer for preparing various culinary dishes is greatly influenced by its texture. Soy paneer should have optimum firmness so that it permits easy cutting and slicing and yet being tender enough to resist crushing during mastication. Therefore, textural properties and yield of soy paneer were evaluated with a view to recommend suitable relevant parameters for the soy industry. Texture was analyzed in terms of hardness, cohesiveness, springiness, chewiness and adhesiveness. A food textural analyzer was used to measure the textural properties of soy paneer.

It was observed that there is an increase in yield with the increase in coagulation temperature. It was found that hardness, cohesiveness, chewiness and adhesiveness increase with coagulation temperature up to $90^{\circ} \mathrm{C}$, whereas springiness increases with coagulation temperature up to $85^{\circ} \mathrm{C}$, remains constant between $85^{\circ} \mathrm{C}$ to $90^{\circ} \mathrm{C}$ and then decreases with the increase in temperature. The developed regression equations can be used to predict these properties within the tested temperature limits.
\end{abstract}

Keywords: Coagulation temperature, soy paneer, textural properties, tofu.

\section{INTRODUCTION}

Paneer is a nutritious heat acid coagulated indigenous milk product, which occupies an important place in the Indian diet. However, the high cost of paneer has restricted its popularity particularly among the middle class and the poor. Milk fat is costly and is a major contributive factor for the increasing occurrence of coronary complications. Hence, there is a considerable interest to reduce or replace the milk fat in paneer. This requires the manufacture of paneer like products utilizing low fat milk from nonconventional food solids (like soybean), which are not only cheap but can also be converted to a product closely similar to the nutritional and textural qualities of paneer. Soybean is highly nutritious, inexpensive, conventional, convenient and one of the richest sources of vegetable protein.

Soy paneer (tofu) is a high protein soy product widely consumed in the orient. It was first introduced to Japan in the year 1183, then to the other Asian countries. Soy paneer has been a very popular food in Eastern Asia since ancient times. It is manufactured by converting soybean into soy milk (5-6\% TS), which in turn is coagulated. Soy paneer is specially rich in protein, fat and minerals as reflected in the Chinese proverb "Tofu is meat without bones". It is prepared using soybean curd, obtained by precipitating proteins from soy milk either with an acid or an alkali salt, which appears like soft white cheese and very firm yoghurt ${ }^{1}$. Soy paneer is a versatile meat or cheese substitute with bland taste and porous texture ${ }^{2}$. Thus, soy paneer could serve as a substitute for milk paneer $^{3}$.

Suitability of soy paneer for preparing various culinary dishes is greatly influenced by its texture. Desirably, paneer should have optimum firmness so that it permits easy cutting and slicing and yet is tender enough to not resist crushing during mastication. Terms like hard, soft, pasty, crumbly, rubbery, chewy, fragile, weak, mealy, coarse have usually been used to describe the texture of paneer ${ }^{4}$. The textural properties of soy paneer play an important role in influencing quality and consumer acceptability. Therefore, the present investigation was undertaken to prepare good textured soy paneer and to 
study the effect of coagulation temperature on yield and other important physical properties of soy paneer.

\section{METHODS AND MATERIALS}

Soybean seeds of the variety "Pooja" were procured from the local market. The coagulant used in the experiment was food grade purified calcium sulfate ${ }^{5}$.

Preparation of soymilk: Soy bean seeds were soaked in water $(1: 3 \mathrm{w} / \mathrm{v})$ for $14-16 \mathrm{~h}$. The soaked water was decanted and the seeds were washed with fresh water. Hundred grams of soaked soybean seeds per litre of water was used for grinding i.e. 1:10 (w/v). The resulting suspension was filtered through a double layered muslin cloth and the filtrate was boiled for $10 \mathrm{~min}$ with continuous stirring to prevent sticking of solids and scorching ${ }^{6}$.

Preparation of soy paneer: Soy paneer was prepared in the laboratory using $5 \mathrm{~L}$ of soymilk for each experiment. A solution of $0.5 \%$ calcium sulfate $\left(\mathrm{CaSO}_{4}\right)$ was used to coagulate soymilk. Soymilk samples were heated to different coagulation temperatures, $80{ }^{\circ} \mathrm{C}, 85{ }^{\circ} \mathrm{C}, 90{ }^{\circ} \mathrm{C}$ and $95{ }^{\circ} \mathrm{C}$. The coagulant was added into soymilk slowly with gentle and continuous stirring. After complete coagulation, stirring was stopped and contents were left undisturbed at room temperature of $30{ }^{\circ} \mathrm{C}$ for $15 \mathrm{~min}$. Whey was then removed by straining through a muslin cloth. The coagulum (soy paneer) thus obtained was pressed at a rate of $1.5 \mathrm{~kg} / \mathrm{cm}^{2}$ for $45 \mathrm{~min}$ in a small sized wooden hoop. Soy paneer was removed from the hoop and soaked in chilled water for $30 \mathrm{~min}$. Then it was taken out and the free water on the surface was removed by wrapping paneer blocks on a clean muslin cloth ${ }^{7}$. The weight of freshly formed tofu was recorded. The soy paneer yield was expressed as $\mathrm{kg}$ soy paneer per $\mathrm{kg}$ of raw dry beans (dry basis) ${ }^{8}$.

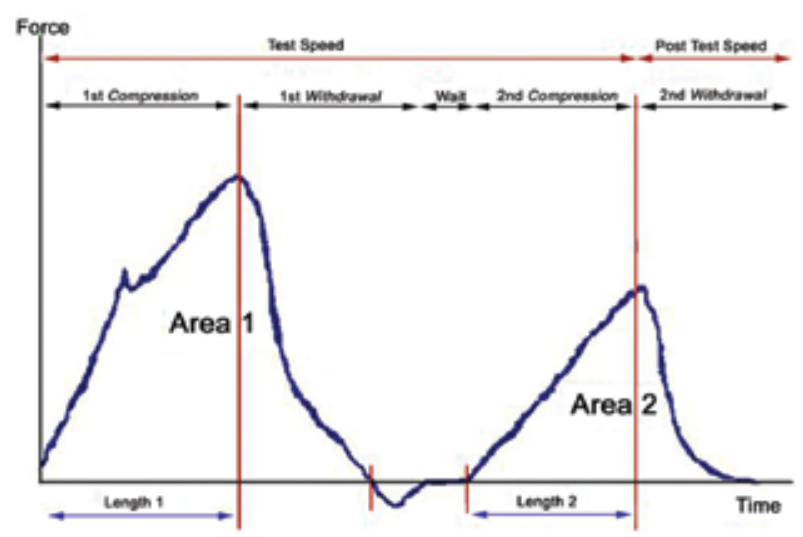

Figure 1: Typical textural profile curve
Determination of textural properties: The textural properties were evaluated using the TA.XTPlus Texture Analyser of Stable Micro System equipped with $5 \mathrm{~kg}$ load cell. The analyzer is linked to a computer that recorded the data via a software programme XT.RA Dimension, version 3.7H (Texture Technologies Corp., New York, USA). Samples of length $80 \mathrm{~mm}$, width $50 \mathrm{~mm}$ and height $40 \mathrm{~mm}$ pieces were cut from the central portion of tofu cake with a stainless steel cutter. A stainless steel probe of $5 \mathrm{~mm}$ diameter with a flat end was used to determine the textural properties. In the first stage, the probe traveled $75 \%$ depth of the soy paneer chunk. The speed of the probe was fixed at $1 \mathrm{mms}^{-1}$ during the pre-test compression of the samples.

Figure 1 shows the typical textural profile curve. The data obtained in the compression test were used for determination of the following textural parameters:

Hardness: It is defined as the value of the peak force of the first compression of the product.

\section{Hardness, $g(H)=$ Maximum force of first compression}

Cohesiveness: Extent to which a material can be deformed before it ruptures depending on the strength of internal bonds.

Cohesiveness $(\mathrm{Ch})=\frac{\text { Area } \text { under the } 1^{\text {st }} \text { compression }}{\text { Area under the } 2^{\text {nd }} \text { compression }}$

Adhesiveness: Force necessary to remove the material that adheres to the mouth when eating food.

Adhesiveness, g. $\mathrm{mm}(A)=$ Negative area in the graph

Springiness: Extent to which a product physically springs back after deformation during the first compression.

Springiness $(S)=$ Length 1/Length 2

Chewiness: Energy required to masticate a solid food product to make it ready for swallowing.

Chewiness, $g(\mathrm{Cw})=$ Hardness $\times$ Cohesiveness $\times$ Springiness

\section{RESULTS AND DISCUSSION}

Texture and rheological properties of most of the coagulated dairy products are based on their structure. The microstructure of these products consists of a continuous protein matrix and status of a loose and open structure with space occupied by the fat globules dispersed through the protein network ${ }^{9}$. The structural arrangement of the network determines the textural characteristics and is affected by factors such as the composition and the 
manufacturing process. Texture profile data for the soy paneer are shown in graphs. The effect of temperature on various textural parameters is presented in graphs with $\pm 5 \%$ accuracy of data points.

\section{Yield}

The yield of soy paneer is of economic importance. The yield is expressed as wet weight of paneer obtained from the dry weight of beans utilized for developing paneer. The yield of soy paneer ranged from 1.4 to $2.5 \mathrm{~kg} / \mathrm{kg}$ dry beans and the yield increased with

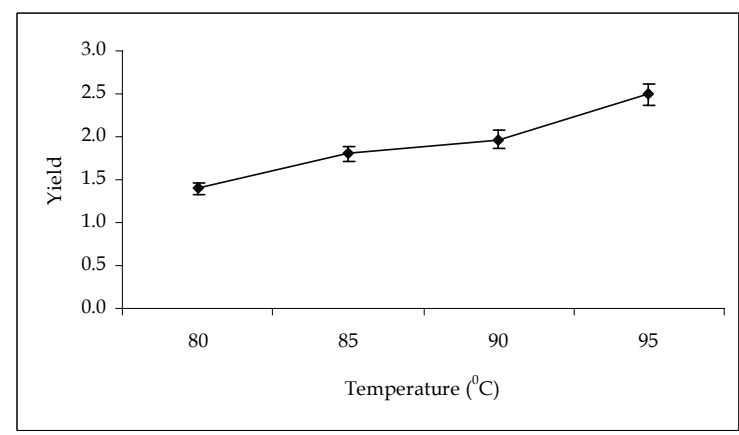

(a) Effect of temperature on yield of soy paneer

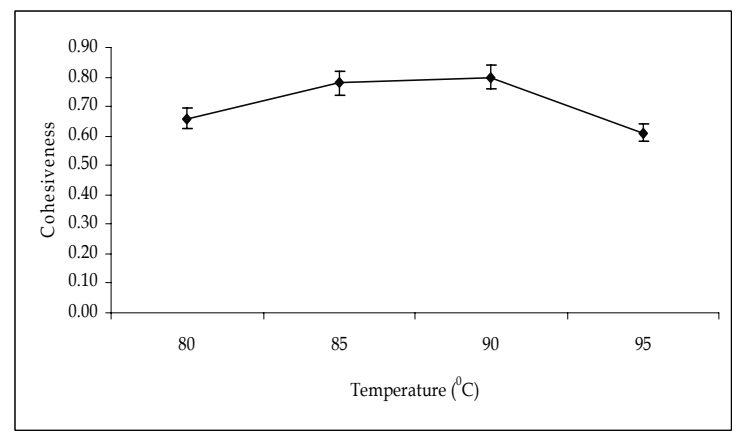

(c) Effect of temperature on cohesiveness of soy paneer

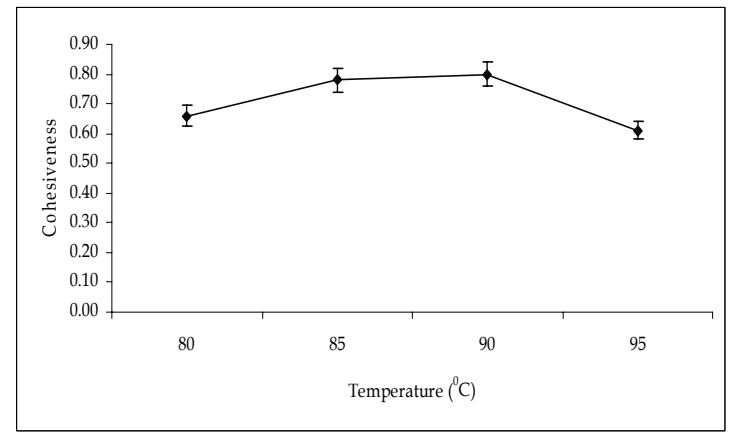

(e) Effect of temperature on chewiness of soy paneer the increase of coagulation temperature. The increase in yield could be due to water being absorbed into the protein matrix. The effect of coagulation temperature on yield of developed soy paneer is presented in Figure 2(a). The following regression equation (Eq.1) was fitted with an $\mathrm{R}^{2}$ value of 0.96 .

$\mathrm{Y}=0.0694 \mathrm{t}-4.155$

where $\mathrm{Y}$ is the yield in $\mathrm{kg} / \mathrm{kg}$ and $\mathrm{t}$ is the coagulation temperature in ${ }^{0} \mathrm{C}$.

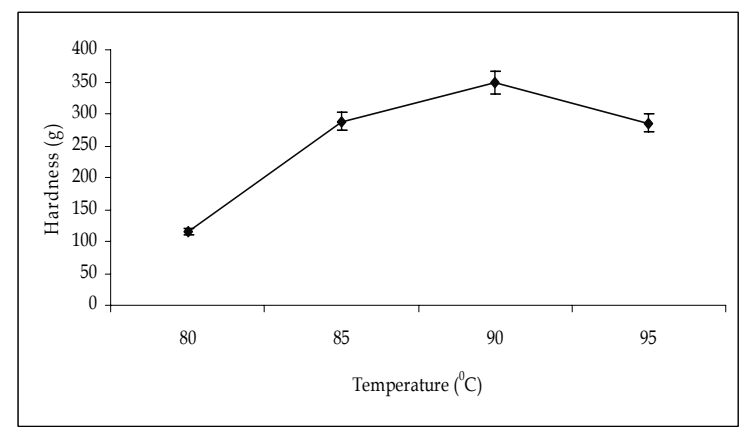

(b) Effect of temperature on hardness of soy paneer

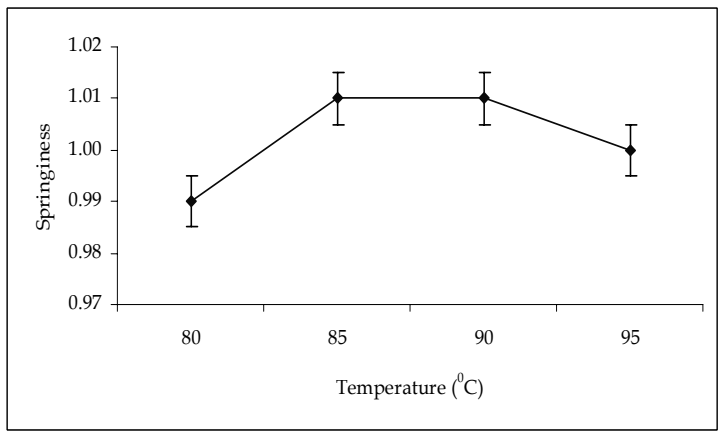

(d) Effect of temperature on springiness of soy paneer

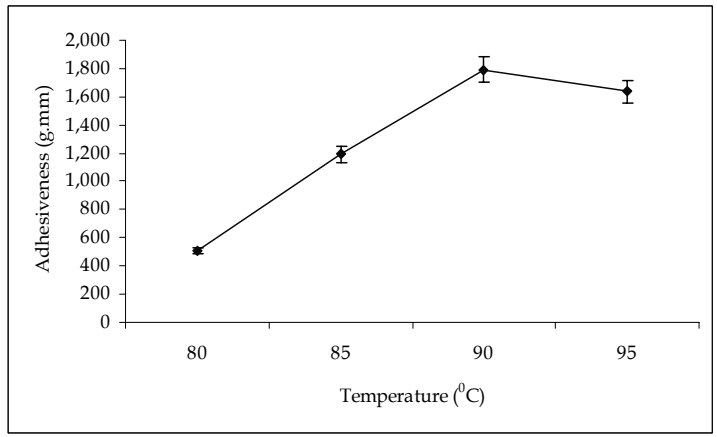

(f) Effect of temperature on adhesiveness of soy paneer

Figure 2 


\section{Hardness}

Hardness is the most commonly evaluated characteristic in determining the texture of paneer. It may be defined as the force necessary to attain a given deformation. The change in hardness of paneer with coagulation temperature is presented in Figure 2(b). It can be seen that the hardness of soy paneer increased as the coagulation temperature increased from $80-90{ }^{\circ} \mathrm{C}$. Similar results were also observed by Saio, $1979^{10}$. However, further increase in the coagulation temperature to $95^{\circ} \mathrm{C}$ decreased the hardness, which may be due to changes occurring in the protein texture at high temperature.

The hardness data were statistically analyzed and regression equation of second order polynomial of the following form is obtained with the correlation coefficient of 0.99 .

$H=-2.346 t^{2}+421.94 t-18626$

where $\mathrm{H}$ is the hardness in $\mathrm{g}$ and $\mathrm{t}$ is the coagulation temperature in ${ }^{\circ} \mathrm{C}$. The high value of the coefficient of determination $\left(\mathrm{R}^{2}=0.99\right)$ indicates the suitability of the Eq. (2) for predicting hardness of the soy paneer within the experimented range of temperature.

\section{Cohesiveness}

Cohesiveness is an important textural property of soy paneer. It is defined as the extent to which a material can be deformed before it ruptures. It depends on the nature of the protein matrix. The effect of coagulation temperature on cohesiveness of developed soy paneer is shown in Figure 2(c). Cohesiveness increased with coagulation temperature up to $90{ }^{\circ} \mathrm{C}$ and with further increase of the coagulation temperature it decreased. Cohesiveness of soy paneer was found in the range 0.66 to 0.80 .

The following regression equation (Eq.3) of second order polynomial has a correlation coefficient $\left(\mathrm{R}^{2}\right)$ of 0.97 .

$\mathrm{Ch}=-0.0031 \mathrm{t}^{2}+0.5399 \mathrm{t}-22.697$

Where, $\mathrm{Ch}$ is the cohesiveness and $\mathrm{t}$ is the coagulation temperature in ${ }^{\circ} \mathrm{C}$.

\section{Springiness}

Springiness is the rate and extent to which a deformed material returns to its original condition after the force is removed. Springiness depends on factors such as heat treatment, protein interaction, flexibility and degree of unfolding of protein ${ }^{11}$. The effect of coagulation temperature on springiness of developed soy paneer is presented in Figure 2(d). Similar to other textural properties, the springiness also increased with increase in coagulation temperature. It increased from 80 to $85^{\circ} \mathrm{C}$ and remains constant at $90{ }^{\circ} \mathrm{C}$. However, springiness declined gradually after $90{ }^{\circ} \mathrm{C}$.

The data of springiness were statistically analyzed and the second order polynomial regression equation (Eq.4) in the following form is fitted with the correlation coefficient of 0.98 .

$\mathrm{S}=-0.0003 \mathrm{t}^{2}+0.0531 \mathrm{t}-1.3375$

where $\mathrm{S}$ is the springiness and $\mathrm{t}$ is the coagulation temperature in ${ }^{0} \mathrm{C}$. However, it is necessary to expand this experiment between $85-90^{\circ} \mathrm{C}$ to find the peak value.

\section{Chewiness}

Chewiness is the energy required to masticate a solid food product to make it ready for swallowing. The effect of coagulation temperature on chewiness of developed soy paneer is presented in Figure 2(e). The chewiness of soy paneer was found to be in the range of $75.7 \mathrm{~g}$ to $281.4 \mathrm{~g}$.

The data of chewiness were fitted in regression equation (Eq.5) of second order polynomial in the following form.

$C_{w}=-2.6 t^{2}+470.35 t-20604$

where $\mathrm{C}_{\mathrm{w}}$ is the chewiness in $\mathrm{g}$ and $\mathrm{t}$ is the coagulation temperature in ${ }^{0} \mathrm{C}$. The correlation coefficient of 0.99 indicates the suitability of the equation for predicting chewiness of soy paneer within the range of temperature tested.

\section{Adhesiveness}

Adhesiveness is the force necessary to remove the material that adheres to the teeth during eating and it is a negative force. The effect of coagulation temperature on adhesiveness of developed soy paneer is presented in Figure 2(f). It can be seen that the adhesiveness of soy paneer increased as the coagulation temperature increased from $80-90^{\circ} \mathrm{C}$. But further increase in the coagulation temperature to $95{ }^{\circ} \mathrm{C}$, decreased adhesiveness. It may be due to the denaturing of protein matrix that contributes to the adhesive forces of the material.

The following regression equation (Eq.6) of second order polynomial has the best fit with the $\mathrm{r}^{2}$ of 0.97 . 
$\mathrm{A}=-8.3 \mathrm{t}^{2}+1545 \mathrm{t}-69539$

where $\mathrm{A}$ is the adhesiveness in $\mathrm{g} . \mathrm{mm}$ and $\mathrm{t}$ is the coagulation temperature in ${ }^{\circ} \mathrm{C}$.

\section{CONCLUSION}

The yield of soy paneer increases with increase of coagulation temperature within the tested range of temperature. It was found that hardness, cohesiveness, chewiness and adhesiveness increases with coagulation temperature up to $90{ }^{\circ} \mathrm{C}$ whereas springiness increases up to $85{ }^{\circ} \mathrm{C}$, remains constant from $85^{\circ} \mathrm{C}$ to $90{ }^{\circ} \mathrm{C}$ and decrease with further increase in temperature. The developed regression equations could be used for predicting these properties in the temperature range of $80-95{ }^{\circ} \mathrm{C}$ with reasonable accuracy. It is important to use a standardized coagulation temperature to produce soy paneer as it affects both yield and quality.

\section{References}

1. Vijayalakshmi K. \& Vaidehi M.P. (1982). Evaluation of tofu and its products prepared from soymilk and combination with sunflower seed milk and skim milk. Journal of Food Science and Technology 19(2):139-142.

2. Tripathi A.K.\& MisraA.K. (2005).Soybean, a consummate functional food: a review. Journal of Food Science and
Technology 42(2): 111-117.

3. Jain A. \& Mittal B.K. (1992). Quality characteristics of paneer prepared from different verieties of soybean. Journal of Food Science and Technology 29(4): 298-300.

4. Sachdeva S. \& Singh S. (1988). Optimization of processing parameters in the manufacture of paneer. Journal of Food Science and Technology 25(2):142-145.

5. Prabhakaran M.P., Perera C.O. \& Valiyaveettil S. (2006). Effect of different coagulants on the isoflavone levels and physical properties of prepared firm tofu. Journal of Food Chemistry 99(3): 492-499.

6. Nasim M., Mittal B.K. \& Tyagi S.M. (1986). Development of a process for preparation of soy paneer. Journal of Food Science and Technology 23(1):69-72.

7. Gangopadhyay S.K. \& Chakraborti S.R. (1992). Technology for preparation of soy paneer. Indian Journal of Diary Science 45(6): 598-600.

8. Sun N. \& Breene W.M. (1991). Calcium sulfate concentration influence on yield and quality of tofu from five soybean varieties. Journal of Food Science 56(6): 1604-1610.

9. Bryant A., Ustunol Z. \& Steff J. (1995). Texture of cheddar cheese as influenced by fat reduction. Journal of Food Science 60(4):1216-1219,1236.

10. Saio K. (1979). Tofu relationships between texture and fine structure. Cereals foods World 24:342-354.

11. Lee C.H. \& Rha C. (1978). Microstructure of soybean protein aggregates and its relation to the physical and textural properties of the curd. Journal of Food Science 43(1):79-82. 